\title{
Can an Electron Gun Solve the Outstanding Problem of Magnetosphere-Ionosphere Connectivity?
}

Gian Luca Delzanno ${ }^{1}$, Joseph E. Borovsky ${ }^{2,3}$, Michelle F. Thomsen ${ }^{4}$, Brian E. Gilchrist ${ }^{3}$, and

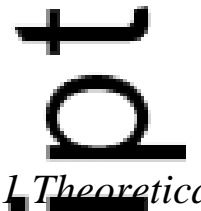
Ennio Sanchez ${ }^{5}$

2 Space Science Institute, Boulder, Colorado, USA

U

3 CSSE, University of Michigan, Ann Arbor, Michigan, USA

4 Planetary Science Institute, Tucson, Arizona, USA

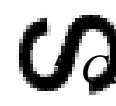
nter for Geospace Science, SRI International, Menlo Park, California, USA

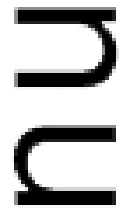

Determining the magnetic connectivity between magnetospheric phenomena and ionosphanenomena is an outstanding problem of magnetospheric and ionospheric physics. Accural establishing this connectivity could answer a variety of long-standing questions. The most-option to solve this is by means of a high-power electron beam fired from a magnosheric spacecraft and spotted at its magnetic footpoint in the ionosphere. This has technical difficulties. Progress has been made on mitigating the major issue of spacecraft chargin the remaining physics issues are identified, together with the need for a synergistic effort my deling, laboratory experiments and, ultimately, testing in space. The goal of this commentary is to stimulate awareness and interest on the magnetosphere-ionosphere conned ivity problem, and possibly accelerate progress towards its solution.

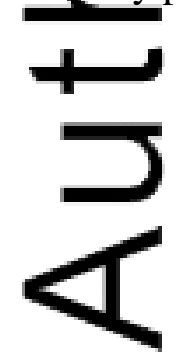

This is the author manuscript accepted for publication and has undergone full peer review but has not been through the copyediting, typesetting, pagination and proofreading process, which may lead to differences between this version and the Version of Record. Please cite this article as doi: 10.1002/2016JA022728

This article is protected by copyright. All rights reserved. 
Corresponding author: G. L. Delzanno, Theoretical Division, Los Alamos National Laboratory, Mail stop: B284, Los Alamos, NM 87545, USA. (delzanno@lanl.gov)

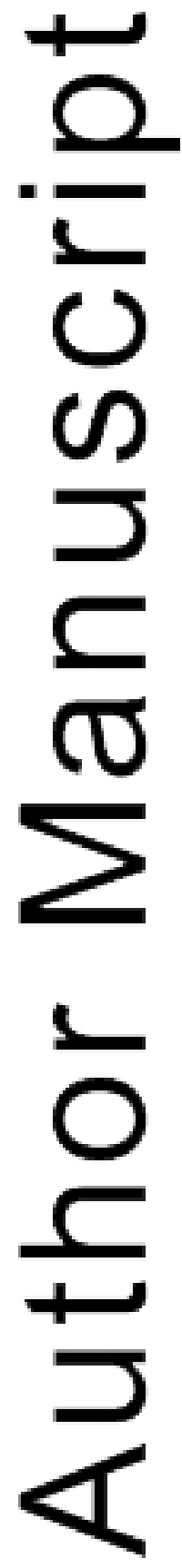

This article is protected by copyright. All rights reserved. 


\section{Introduction}

A complex system, like the magnetosphere-ionosphere-thermosphere (M-I-T) system, is a collection of diverse, connected, interacting entities. In the solar-wind-driven M-I-T system, we have not been able to establish many of the fundamental connections and ascertain the mechatisms of the essential couplings. To build system models, we need to determine how critical phen omena in the ionosphere and critical phenomena in the magnetosphere are connected. (Note that here and in the following we use the term 'connection' instead of 'coupling' to disting betwee a grtain region of the magnetosphere with the corresponding region of the ionosphere.) Magnetosphere-ionosphere connections are determined with magnetic-field models, or with mulc-field models constrained by spacecraft measurements [Tsyganenko and Usmanov, 1982; Fsygognenko, 1989; Tsyganenko and Sitnov, 2007]. Accurately connecting magnetospheric phenomena to ionospheric phenomena is difficult because the magnetospheric magnetic field has

localiz dime variations that are not captured in magnetic-field models. The magnetosphere is a high-Reundds-number system and, like turbulence, attempting to predict these localized magnetr-ld perturbations would be ill conceived. Tests of magnetic-field models over the years 1 accuracy at best for mapping magnetospheric measurements to the ionosphere, with wors accuracy as activity increases [Weiss et al., 1997; Ober et al., 2000; Shevchenko et al., 2010; Nishimura et al., 2011]. Note that $1^{\circ}$ in the ionosphere is a substantial fraction of the width of the Entire_auroral zone [e.g. Weimer et al., 1985; Feldstein and Galperin, 1985].

magnetospneric location of the growth-phase arc prevents us from determining magnetospheric proces es that may be key to substorm initiation. More generally, not being able to connect magnerosnhric measurements to specific types of aurora prevents us from knowing the various causes conditions for the various types of aurora and prevents us from discerning how energy extracted from the magnetosphere to power the aurora. Controversies over the ionosner c signatures of flow structures in the magnetotail prevent us from using the aurora as a 
diagnostic of magnetospheric dynamics. Uncertainties on the location of the sub-auroral polarization stream (SAPS) with respect to the plasmapause, the location of substorm sub-auroral ion drifts (SAID) with respect to injection fronts, and the location of the Harang discontinuity in the magnetosphere prevent us from gaining full understanding of the physics and impacts of those fnenomena. The ionospheric footpoint of the near-Earth neutral line is a tantalizing myster 2

- There are other techniques to overcome the magnetosphere-ionosphere connectivity proble they are limited in what they can map and when. Matching low-altitude particle distrib tionfunctions to equatorial distribution functions works under the rare occasions when there are spacecraft magnetic conjunctions [Meng et al., 1979; Hones et al., 1996; Weiss et al., 1997]. Cosing isotropy boundaries [Sergeev et al., 1993; Shevchenko et al., 2010] or sheet currents [MT toba et al., 2015], both with distinct ionospheric signatures, allows one to constrain the latitudinal (but not longitudinal) mapping of these features. Connecting up time signatures of plasmawaves measured in the magnetosphere with time signatures of auroral pulsations allows a spacecraft be mapped into a pulsating patch [Jaynes et al., 2015] in the pulsating diffuse aurora $\mathrm{dubstorm}$ recovery times. Of course, conjugate auroral features in the northern and southomisphere can be mapped to each other [Stenbaek-Nielsen et al., 1972; Østgaard et al., 2011 witho information about the magnetospheric connection.

A robust, versatile, and definitive solution to the outstanding problem of magnetosphereionospare connectivity is to use a high-power electron beam fired into the atmospheric loss cone from magnetospheric spacecraft to produce a detectable (optical or radar) beam spot in the atmospnere. A major difficulty of this approach is that the tenuous magnetospheric plasma cannot rovide the return current necessary to compensate for the electron beam current. In these conditions, he spacecraft charges to such high levels that the electron beam is electrostatically pulled Indeed, fear of catastrophic spacecraft charging is the main reason why this idea has never becrealized in practice and remains identified as an outstanding emerging-technology

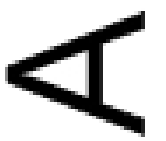


problem in the recent decadal survey of solar and space physics [National Research Council, 2012; MacDonald et al., 2012].

\section{The charging problem and a promising solution}

In order to put the spacecraft charging problem in perspective, let us consider a 4-kW electro begm with current $\mathrm{I}=0.1 \mathrm{~A}$ and energy $\mathrm{E}=40 \mathrm{keV}$ emitted by a spacecraft at geosynchronous orbit. Representative local plasma conditions are the plasma density $\mathrm{n}=1 \mathrm{~cm}^{-3}$ and eletron.temperature $\mathrm{T}=1 \mathrm{keV}$. One can easily calculate the equilibrium spacecraft potential by bala cing the beam current with the current collected by the spacecraft from the background magnetized plasma [Hastings and Garrett, 1996]. Assuming spherical symmetry, the framework of the rbtal-Motion-Limited theory [Mott-Smith and Langmuir, 1926] predicts that the spacecrartyould charge to about $10^{7} \mathrm{~V}$, significantly higher than the beam energy, implying that beam emission would not be possible [Delzanno et al., 2015b].

A possible charging mitigation strategy, often used onboard spacecraft or on the Internations Space Station, involves a high-density charge-neutral plasma fired prior to and during thectron beam. This plasma is normally referred to as the contactor plasma, since its purpose-1s to "make contact" with the background and effectively increase the collection area of the sacecraft [Olsen, 1985; Schmidt et al., 1995; Comfort et al., 1998; Torkar et al., 2001]. Assume that the contactor is operated prior to the beam to create a plume of $5 \mathrm{~km}$ diameter contactng the spacecraft, and that the $\mathrm{I}=0.1 \mathrm{~A}$ beam is fired for $1 \mathrm{~s}$ leaving $0.1 \mathrm{C}$ on the spacecratt. For reference, $1 \mathrm{C}$ is a lightning-bolt worth of charge [cf. Krehbiel et al., 1979; Table 7. of Uman, 1987].) If this charge is passed to the spacecraft-contactor system, a straigh forward application of Coulomb's law with a radius of $2.5 \mathrm{~km}$ gives a potential of $400 \mathrm{kV}$. Such Goulomb's law arguments imply that the residual charge from the beam must be rapidly moved som the spacecraft (i.e. to very large radius) and not simply into the contactor plume.

Irtorder to shed light on the feasibility of using a contactor charging mitigation scheme for thiment, Delzanno et al. [2015a,b] performed an extensive simulation campaign of 
the beam-spacecraft-contactor-background plasma system. They found that the contactor cannot really be used in an electron collection mode since the collisionless contactor plume is essentially transparent to any ambient electron that might be collected and fails to deliver a significantly larger current to the spacecraft. However, if the contactor current is larger than the beam current, the colrtactor can be used as an emitter of net positive charge (referred to as "ion emission"). Physic his is because the contactor enables ion emission off its quasi-spherical surface, where the Child-Langmuir space-charge limit (that is well-known to strongly reduce the emissidnofan ion beam in planar geometry) is not a problem [Delzanno et al., 2015a]. Although the simalatypns were only describing the early evolution of a real experiment, the end result is that the transient of the spacecraft potential can be effectively mitigated by the ion emission from the contat plume.

\section{Open issues}

While the results of Delzanno et al. [2015a,b] might provide a pathway for high-power electrop-am experiments to operate in the low-density magnetosphere, several open issues, discuss dow, must be resolved to establish these ideas conclusively.

Exacecraft-and-plume charging for a long beampulse. The simulation results discyabove describe the early evolution of a real experiment. Simple algebraic estimates for a long (1-s) beampulse for a spacecraft-plume system in vacuum indicate that the system will charge onseyeral $10 \mathrm{~s}$ of $\mathrm{kV}$. Indications are that the presence of ambient magnetospheric protons will gr atry aid in the transport of positive charge away from the spacecraft plume system, reducing ire long-beampulse potentials. Simulations of the long-time evolution of the system are needed

Geometrical shape of $\mathbf{k m}$-sized contactor plumes. One unknown for such longbeampulations is the geometrical shape of the $\mathrm{km}$-sized plasma-contactor plume. All simulations [e.g. Roy et al., 1996; Wang et al., 2001; Boyd, 2006], laboratory measurements [e.g. Ohle 1., 1995; Gallimore, 2001; Walker and Gallimore, 2005; Beal et al., 2005], and space 
measurements [e.g. Boyd, 2002; Gabdullin et al., 2008] of plumes deal only with the nearspacecraft morphology and dynamics. There are outstanding questions about the evolution of the collisionless plume propagating both parallel to and across the magnetospheric magnetic field. To investigate all of the collisionless-plasma phenomena that govern the plume evolution (e.g. charge-polarization, Alfven wings, structuring) almost certainly will require three-dimensional particl sim lations with very large dynamic ranges.

- Ream energy. Major tradeoffs for a magnetospheric experiment involve the choice of a few-M $\mathbf{l}$ electron beam versus a 10 s-of-keV electron beam. A major advantage to the $\mathrm{MeV}$ choice that, for the same beam power, much less charge is removed from the spacecraft by an $\mathrm{MeV}$ beam than by a keV beam. This reduces spacecraft-charging risk and simplifies the beamcontactorations. Further, if uncontrolled spacecraft-plume charging does occur, the aiming of an Meveam is less perturbed by the electrical potentials than is the aiming of a keV beam. The MeV-versus-keV choice results in very different gun designs and power-conversion methodologies, with keV designs having some spaceflight heritage. Because energy storage for such a metospheric experiment will dominate the payload mass, energy efficiency (from stored endy to energy deposited in the atmosphere) of the gun/power-conversion design is an imporant consideration. MeV guns can be designed to produce electron beams with less beam diver than $\mathrm{keV}$ guns can, making it easier to inject the full beam power into the atmospheric loss cone to prevent wasting beam power. keV guns have an advantage that the

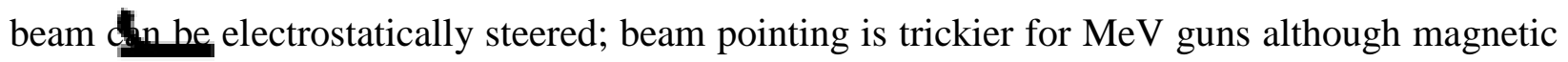
steerag Is promising. For $\mathrm{MeV}$ electron beams, relativistic effects displace the loss cone away from the magnetic-field-line direction and must be accounted for to maximize beam aiming to hit the atmosphere [Porazik et al., 2014]. This can be accomplished once the B-field orientation (as in the traditional loss-cone calculation) and its curvature are known. For equatorial distances less than aburath $R_{E}\left(R_{E}\right.$ is the Earth radius) one could safely use the dipole field approximation but for larger distances the effect of a more realistic magnetic field configuration can become $\varangle$ 
important. Empirical magnetic-field models should be used to assess the loss-cone variation for particles of different energies injected at various equatorial distances.

Beam propagation. Beam scattering by instabilities could prevent the beam electrons from reaching the atmosphere. Early work on the propagation of cylindrical-shaped nonrelativistic electron beams through plasmas indicated that the growth lengths for instabilities were lrger than the magnetosphere [Galvez and Borovsky, 1988]: indeed rocket-fired keV beams have been detected after making transits along the magnetic field through the magne 1992; rae sky and Tríska, 1993; Choueri et al., 2001]. Theoretical instability assessment of $\mathrm{MeV}$-energy electron beams in the magnetosphere has not yet been performed. A related issue to be stu(d) scattering of $\mathrm{keV}$ and $\mathrm{MeV}$ electron beams by the natural plasma-wave environmengs of the magnetosphere.

Beam detection. Locating the beamspot in the nighttime atmosphere with the use of groundbased optical equipment is straightforward [Borovsky, 2002; Marshall et al., 2014], providinafficient beam power $(\sim 10 \mathrm{~kW})$ is deposited in the atmosphere. Using prompt (unquench) airglow emission lines, a blink technique (a beam-on beam-off sequence synchraized between the gun and the ground-based cameras) can be used to discern the beam in an auroral-emission background. The possibility of detection of the ionization of the beamspot with ground-based radars [e.g. Zhulin et al., 1980; Uspensky et al., 1980; Izhovkina et al., 1901 may allow the detection of beams fired from the dayside magnetosphere; for radar detectig (ran MeV-versus-keV energy tradeoff is involved [Marshall et al., 2014].

\section{Con lusions}

The mbility to connect unambiguously phenomena occurring over vast regions of nearEarth could solve a variety of long-standing problems in magnetospheric/ionospheric physics and open a new field of experimental space plasma physics. In principle, it could be accomen hed by a high-power electron beam fired from a magnetospheric spacecraft and 
traveling along the magnetic field line to its ionospheric footpoint. Recent progress demonstrates that the once-overwhelming problem of catastrophic spacecraft charging can be mitigated by a plasma contactor operating in an ion emission mode. As called for in the decadal survey [National Research Council, 2012], a lot of preparatory science is still necessary to establish this missiolconcept conclusively. This paper attempts to provide a roadmap for the resolution of the most mpotant issues, emphasizing that a synergistic effort of theoretical/computational modeling and laboratory experiments is needed to achieve risk mitigation. Still, the ultimate proof of the feasibility of these ideas will have to come from space experiments.

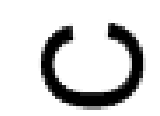

Ackno 1 dements: This work contains no new data. This work was funded by the Laboratory Directearissearch and Development program (LDRD) and by Los Alamos National Laboratory institutional research funds through the Center of Space and Earth Science (CSES), under the auspicds of the National Nuclear Security Administration of the U.S. Department of Energy by Los Alamational Laboratory, operated by Los Alamos National Security LLC under contract DE-AC526NA25396. J.E.B. was funded by the NASA LWS TRT program, the NASA magnesperic GI program, and the NASA Geospace SRT program.

\section{Referehces.}

Beal, B C. A. D. Gallimore, and W. A. Hargus (2005), Plasma properties downstream of a lowpower Hall thruster, Phys. Plasmas, 12, 123503.

Borovs $\mathrm{y}$, J. (2002), The magnetosphere-ionosphere observatory (MIO), Los Alamos National Laboratory, http://www.lanl.gov/csse/MIOwriteup.pdf.

Boyd, (2002), Hall thruster plasma plume modeling and comparison to express flight data, 40tr-Rerospace Sciences Meeting and Exhibit, AIAA-2002-0487, Reno, Nevada, 14-17 antery. 
Boyd, I. D. (2006), Numerical simulation of Hall thruster plasma plumes in space, IEEE Trans. Plasma Sci., 34, 2140.

Comfort, R. H., T. E. Moore, P. D. Craven, C. J. Pollock, F. S. Mozer, and W. S. Williamson (1998), Spacecraft potential control by the Plasma Source Instrument on the POLAR satentite, J. Spacecraft Rockets, 35, 845.

Delzan o, 9. L., J. E. Borovsky, M. F. Thomsen, J. D. Moulton and E. A. MacDonald (2015a),

Future heam experiments in the magnetosphere with plasma contactors: How do we get the chlroeoff the spacecraft?, J. Geophys. Res., 120(5), 3647.

Delzan IO, Y. L., J. E. Borovsky, M. F. Thomsen, and J. D. Moulton (2015b), Future beam experiments in the magnetosphere with plasma contactors: the electron collection and ion entis iph routes, J. Geophys. Res., 120(5), 3588.

Feldstem, I., and Y. I. Galperin (1985), The auroral luminosity structure in the high-latitude upper atmosphere: Its dynamics and relationship to the large-scale structure of the Earth's magetosphere, Rev. Geophys., 23, 217.

Gabdullin_F. F., A. G. Korsun, and E. M. Tverdokhlebova (2008), The Plasma Plume Emitted Onoow the International Space Station Under the Effect of the Geomagnetic Field, IEEE Trus. On Plasma Sci., 36, 5.

Gallinore (2001), Near- and far-field characterization of stationary plasma thruster plumes, $J$. Spacecraft Rockets, 38, 441.

Galve_M_and J. E. Borovsky (1988), The electrostatic two-stream instability driven by slabshopeand cylindrical beams injected into plasmas, Phys. Fluids, 31, 857.

Hallinan, 1. J., H. C. Stenbaek-Nielsen, and J. R. Winckler (1978), The Echo 4 electron beam ex eriment: Television observation of artificial auroral streaks indicating strong beam interaction in the high-latitude magnetosphere, J. Geophys. Res., 83, 3263.

Hasting., and H. Garrett (1996), Spacecraft-Environment Interactions, Cambridge, Camondge University Press.

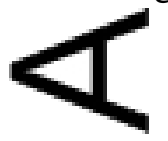


Hones, E. W., M. F. Thomsen, G. D. Reeves, L. A. Weiss, D. J. McComas, and P. T. Newell (1996), Observational determination of magnetic connectivity of the geosynchronous region of the magnetosphere to the auroral oval, J. Geophys. Res., 101, 2629.

Izhovkina, N. I., J. C. Kosik, A. K. Pyatsi, H. Reme, A. Saint-Marc, J. L. Sverdlov, M. V. Gspensky, J. M. Vigo, J. F. Zarnitsky, and I. A. Zhulin (1980), Comparison between ex erimental and theoretical conjugate points locations in the Araks experiments, Ann. Geanhus., 36, 319.

Jaynes ., M. R. Lessard, K. Takahashi, A. F. Ali, D. M. Malaspina, R. G. Michell, E. L. Spans ijk, D. N. Baker, J. B. Blake, C. Cully, E. F. Donovan, C. A. Kletzing, G. D. Reeves, M. Samara, H. E. Spence, and J. R. Wygant (2015), Correlated Pc4-5 ULF waves, whistlermChorus, and pulsating aurora observed by the Van Allen Probes and ground-based systemy J. Geophys. Res., 120, 8749.

Krehbiel, P. R., M. Brook, and R. A. McCrory (1979), An analysis of the charge structure of lighing discharges to ground, J. Geophys. Res., 84, 2432.

Lavergnat (1982), The French-Soviet experiment ARAKS: Main results, in Artificial Particle Beoms n Space Plasma Studies, B. Grandal (ed.), pg. 87, New York, Plenum.

Nishmma,Y., J. Bortnik, W. Li, R. M. Thorne, L. R. Lyons, V. Angelopoulos, S. B. Mende, J. Panell. O. Le Contel, C. Cully, R. Ergun, and U. Auster (2011), Estimation of magnetic field mapping accuracy using the pulsating aurora-chorus connection, Geophys. Res. Lett., $38 \mathbf{L} 1410$.

MacDoraty E. A., J. E. Borovsky, B. Larsen, and E. Dors (2012), A science mission concept to activery probe magnetosphere-ionosphere coupling, Decadal Survey in Solar and Space Ph sics 2012, Paper 171.

Marshall_R_A., M. Nicholls, E. Sanchez, N. G. Lehtinen, and j. Nellson (2014), Diagnostics of an 8560

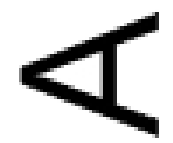


Meng, C.-I., B. Mauk, and C. E. McIlwain (1979), Electron precipitation of evening diffuse aurora and its conjugate electron fluxes near the magnetospheric equator, J. Geophys. Res., $84,2545$.

Motoba, T., S. Ohtani, B. J. Anderson, H. Korth, D. Mitchell, L. J. Lanzerotti, K. Shiokawa, M. conners, C. A. Kletzing, and G. D. Reeves (2015), On the formation and origin of substorm gr wth phase/onset auroral arcs inferred from conjugate space-ground observations, $J$. Geonhus. Res., 120, 8707.

Mott-Shith_H., and I. Langmuir (1926), The Theory of Collectors in Gaseous Discharges, Phssica. Review, 28, 727.

National Research Council (2012), Magnetosphere-to-ionosphere field-line tracing technology, in 6 and Space Physics: A Science for a Technological Society, pg. 333, Washington DC, Nattonty Academies Press.

Ober, D. M., N. C. Maynard, W. J. Burke, J. Moen, A. Egeland, P. E. Sandhold, C. J. Farrugia, E. J. Weber, and J. D. Scudder (2000), Mapping prenoon auroral structures to the mapatosphere, J. Geophys. Res., 105, 27519.

Olsen, R. (1985), Experiments in charge control at geosynchronous orbit -- ATS-5 and ATS-6, S. Snacecraft, 22, 254.

Ohle G. B. E. Gilchrist, and A. D. Gallimore (1995), Non-intrusive electron number density measurements in the plume of a $1 \mathrm{~kW}$ arcjet using a modern microwave interferometer, IE E Trans. Plasma Science, 23 (3), 428.

Oraevsy, N., and P. Tríska (1993), Active plasma experiment - Project APEX, Adv. Space Res., 13, 103.

Choue E., V. N. Oraevsky, V. S. Dokukin, A. S. Volokitin, S. A. Pulinets, Y. Y. Ruzhin, and V. Vyafomin (2001), Observations and modeling of neutral gas releases from the APEX satid. Geophys. Res., 106, A11, 25,673.

Østgaaru, 1., B. K. Humberset, and K. M. Laundal (2011), Evolution of auroral asymmetries in njugate hemispheres during two substorms, Geophys. Res. Lett., 38, L03101. 
Pellat, R., and R. Z., Sagdeev (1980), Concluding remarks on the ARAKS experiments, Ann. Geophys., 36, 443.

Porazik, P., J. R. Johnson, I. Kaganovich, and E. Sanchez (2014), Modification of the loss cone for energetic particles, Geophys. Res. Lett., 41, 8107.

Roy, K.T. S., D. E. Hastings, and S. Taylor (1996), Three-dimensional plasma particle-in-cell ca culatons of ion thruster backflow contamination, J. Comp. Phys., 128, 6.

Schmid_R H. Arends, A. Pedersen, F. Rudenauer, M. Fehringer, B. T. Narheim, R. Svens, K. K rnsyeen, K. Tsuruda, T. Mukai, H. Hayakawa, and M. nakamura (1995), Results from ac Ne spacecraft potential control on the Geotail spacecraft, J. Geophys. Res., 100, 17253.

Sergeev, A., M. Malkov, and K. Mursula (1993), Testing the isotropic boundary algorithm m. A to evaluate the magnetic field configuration in the tail, J. Geophys. Res., 98, 7609.

Shevchenky I. G., V. Sergeev, M. Kubyshkina, V. Angelopoulos, K. H. Glassmeier, and H. J. Singer (2010), Estimation of magnetosphere-ionosphere mapping accuracy using isotropy bo ndary and THEMIS observations, J. Geophys. Res., 115, A11206.

Stenbae-Nielsen, H. C., T. N. Davis, and N. W. Glass (1972), Relative motion of auroral conjugde points during substorms, J. Geophys. Res., 77, 1844.

Torkar. Riedler, C. P. Escoubet, et al. (2001), Active spacecraft potential for Cluster -mementation and first results, Ann. Geophys., 19, 1289.

Tsyganenko, N. A., and A. V. Usmanov (1982), Determination of the magnetospheric current sy tem parameters and development of experimental field models based on data from IMP an $17 y$ S satellites, Planet. Space Sci., 30, 985.

Tsyganemro, N. A. (1989), A magnetospheric magnetic field model with a warped tail current sh et, Planet. Space Sci., 37, 5.

Tsygarenko N. A., and M. I. Sitnov (2007), Magnetospheric configurations from a high remon data-based magnetic field model, J. Geophys. Res., 112, A06225.

Uman, (1987), The Lightning Discharge, Orlando, Academic Press.

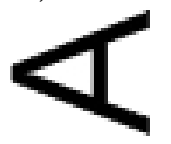


Uspensky, M. V., E. E. Timopheev, and Y. L. Sverdlov (1980), ARAKS doppler radar measurements of the ionospheric effects of artificial electron beams in the North hemisphere, Ann. Geophys., 36, 303.

Wang, J., D. Brinza, and M. Young (2001), Three-dimensional particle simulations of ion propuision plasma environment for Deep Space 1, J. Spacecraft Rockets, 38, 433.

Weim D. R., C. K. Goertz, D. A. Gurnett, N. C. Maynard, and J. L. Burch (1985), Auroral zoneelectric fields from DE1 and 2 at magnetic conjuctions, J. Geophys. Res., 90, 7479.

Weiss M. F. Thomsen, G. D. Reeves, and D. J. McComas (1997), An examination of the Ts gan nko (T89A) field model using a database of two-satellite magnetic conjunctions, $J$. Geophys. Res., 102, 4911.

Winck R. (1992), Controlled experiments in the Earth's magnetosphere with artificial electro beams, Rev. Modern Phys., 64, 859.

Zhulin, T. A., A. V. Kustov, M. V. Uspensky, and T. V. Miroshnikova (1980), Radar ob ervations of the overdense ionospheric ionization created by the artificial electron beam in tha "Zarnitza-2" experiment, Ann. Geophys., 36, 313.
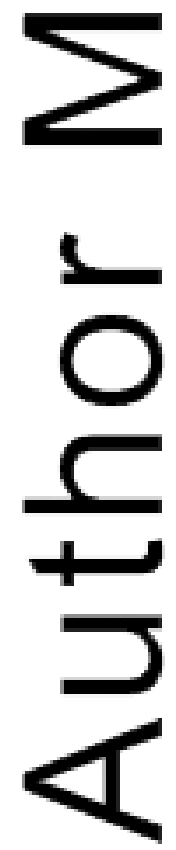